Case Report

\title{
Atypical Infections in Chronic Myeloid Leukaemia- Staphylococcus furunculosis and Aspergillosis
}

\author{
Sharon T Mathews', Naresh Kumar², Sandeep Garg ${ }^{3}$, Bhavana Mastebhakti'
}

${ }^{1}$ Assistant Professor, ${ }^{3}$ Professor, ${ }^{4}$ Postgraduate Resident, Department of Medicine, Maulana Azad Medical College, New Delhi, India.

${ }^{2}$ Professor of Medicine \& Head, Pulmonary Medicine, Maulana Azad Medical College, New Delhi, India.

DOI: https://doi.org/10.24321/2349.7181.202004

I $\quad \begin{array}{lllll}\mathbf{N} & \mathbf{F} & \mathbf{O}\end{array}$

\section{Corresponding Author:}

Sharon T Mathews, Department of Medicine, Maulana Azad Medical College, New Delhi, India.

E-mail Id:

sharontmathews@gmail.com

Orcid Id:

https://orcid.org/0000-0003-2257-9909

How to cite this article:

Mathews ST, Kumar N, Garg S, Mastebhakti B. Atypical Infections in Chronic Myeloid LeukaemiaStaphylococcus furunculosis and Aspergillosis. J Adv Res Med 2020; 7(1): 17-19.

Date of Submission: 2020-07-25

Date of Acceptance: 2020-08-11

\section{$\begin{array}{llllllll}\mathbf{A} & \mathbf{B} & \mathbf{S} & \mathbf{T} & \mathbf{R} & \mathbf{A} & \mathbf{C} & \mathbf{T}\end{array}$}

Incidence of opportunistic infection in patients of Chronic Myeloid Leukemia (CML) on Imatinib therapy is low. We report a case of a 47 year old lady, a known case of CML for one year on imatinib therapy who presented with CML in blast crisis with Staphylococcus furunculosis. Two weeks later she developed fever, cough and expectoration. She had cavitatory lesion in the right middle zone on chest $\mathrm{x}$-ray. CECT Chest was suggestive of aspergilloma in right middle lobe. Infections in chronic myeloid leukemia are not very common. Also, developing such infections within such a short span of time, within one year of initiation of imatinib therapy is also rare. Hence, this case of CML with Staphylococcal furunculosis and Aspergillosis is being reported.

Keywords: Chronic, Myeloid Leukemia, Atypical Infections, Furunculosis, Aspergillosis, Imatinib

\section{Introduction}

Imatinib is now the widely accepted first line therapy of Chronic Myeloid Leukemia (CML) for several years. Incidence of opportunistic infections in patients of CML on Imatinib therapy is low ${ }^{1}$ However, evidences are there that imatinib can impair many cellular functions involved in immune response particularly in cell-mediated immunity. ${ }^{2-4}$

Many cases of Staphylococcal infections and invasive fungal infections have been reported in acute leukaemias but very few have been reported in chronic leukaemia. Opportunistic infections are an unusual complication also in a real life population of Chronic Phase - CML patients under imatinib therapy.

HIV co-existing with CML, EBV associated leucoplakia of tongue in a CML patient on treatment with dasatinib, EBV lymphoproliferative disease in CML patient on treatment with Imatinib, disseminated atypical mycobacterial infections have been reported in three cases of CML, mediastinal abscess due to aspergillus in patient with atypical CML, BCR-ABL gene negative, Varicella infection in $16 \mathrm{CML}$ patients on imatinib therapy are few of the others which have been reported. $5,6,7,8,9,10$

We are reporting this case of CML in blast crisis phase presenting with two atypical infections.

\section{Case Report}

A 47 year old lady, known case of CML in chronic phase for last one year on imatinib $400 \mathrm{mg} /$ day, presented to us with leucopenia. Dose of imatinib was decreased from $400 \mathrm{mg} /$ day to $300 \mathrm{mg} /$ day. She was advised to visit us on weekly basis but did not report for three weeks. Three weeks later, she presented with fever and multiple pustules over face and neck of ten days duration. She had no complains of 
bleeding from any site, cough breathlessness, abdominal pain, vomiting and burning micturition. On examination, she was pale. She had multiple pustules over her face and neck. Systemic examination was normal.

Investigations revealed hemoglobin of $6.4 \mathrm{gm} \%$, TLC-3070 cells/cu.mm, N-18\%, E-20\%, Blasts- $60 \%$, platelet -1.53 cells/ cu.mm, urea- $54 \mathrm{mg} / \mathrm{dL}$, creatinine- $1.7 \mathrm{mg} / \mathrm{dL}$, S. Ca-7.6 $\mathrm{mg} / \mathrm{dL}$, S.PO4-3.2 mg/dL, S.uric acid- $13.9 \mathrm{mg} / \mathrm{dL}$. CXR was normal. Pus from pustule was sent for gram stain which was found to be full of gram positive cocci in groups. Pus culture was suggestive of Staphylococcus aureus. Pus smear revealed degenerated histiocytes with plenty of polymorphs. Qualitative PCR from pus was negative for Tubercular bacilli.

She was treated with IV Amoxicillin \& Clavulanic acid and IV Clindamycin according to pus $\mathrm{c} / \mathrm{s}$ report. Patient responded to the treatment and recovered. Tab imatinib was increased to $600 \mathrm{mg}$ OD. Flow cytometry -T3151 mutation was found to be negative.

Two weeks later, during hospital stay, she developed low grade fever and cough with minimal whitish sputum. CXR revealed right mid zone cavitatory lesion. NCCT chest showed a well defined, cavitatory lesion in the right middle lobe with rounded soft tissue content surrounded by a crescent of air (Figure 1). The adjacent lung parenchyma showed ground glassing. Features were suggestive of infective etiology with cavitory lesion likely to be a fungal ball. Haemogram revealed an $\mathrm{Hb}$ of $7.7 \mathrm{gm} \%$, TLC-3630 Cells/cu.mm, Blasts-32\%. Patient was started on inj. Meropenem, Inj. Amphotericin B and Tab Imatinib 800mg OD. Bone marrow aspiration biopsy was suggestive of chronic myeloid leukemia with secondary myelofibrosis with myeloid blast crisis. Patient had a fall while going to the bathroom during hospital stay and sustained head injury to which she succumbed to.

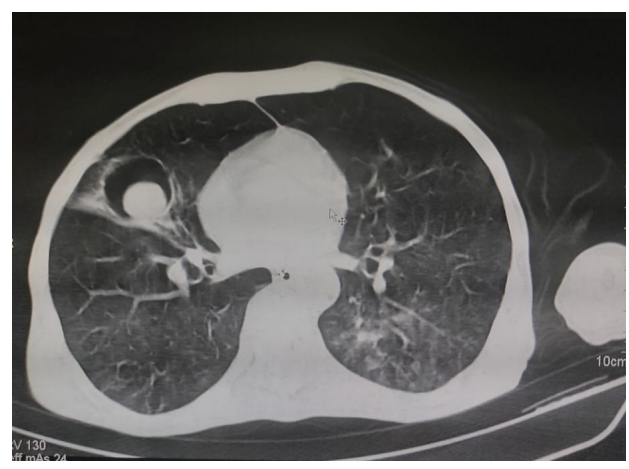

Figure I.NCCT Chest showing a well defined, cavitatory lesion of size $3.6 \times 3.8 \mathrm{~cm}$ in the Rt. middle lobe with rounded soft tissue content within surrounded by a crescent of air (Monod Sign). Associated ground glassing of adjacent lung parenchyma and adjacent focal pleural thickening

\section{Discussion}

In this report, we describe a patient of $\mathrm{CML}$ in blast crisis phase who developed Staphylococcal furunculosis which resolved by treatment with antibiotics and later developed right middle lobe pneumonia as a result of Aspergillosis. Infections in CML in blast crisis phase has not been reported much. A case of Corynebacterium minutissimum bacteremia in a patient with CML in blast crisis phase has been reported earlier. $^{11}$

Incidence of fungal infection is highest among patients with acute myeloid leukemia. ${ }^{12}$ Aspergillus species are still the most common pathogens, followed by Candida species. ${ }^{12}$ Patients with hematologic malignancies are currently at higher risk of invasive fungal infection caused by molds than by yeasts. ${ }^{12}$ Overall mortality rate and invasive fungal infection-attributable mortality rates were $2 \%$ and $39 \%$, respectively. ${ }^{12}$ The attributable mortality rate for aspergillosis has dropped from $60-70 \%$ to approximately $40 \% .{ }^{12}$ Three cases of invasive aspergillosis in CML patients on Tyrosine Kinase Inhibitors (TKI) have been reported. In those cases there were no traditional risk factors and TKI were even withdrawn for greater clinical improvement. ${ }^{13}$ Though in our case we could not find out the outcome of the disease activity as the patient succumbed to another cause of death.

CML patients in chronic phase are at low risk of infection compared to patients in more advanced disease phases, however, the epidemiological impact of infectious complications in the imatinib era is unknown as infections have not been considered in the safety analysis of large imatinib studies. ${ }^{14,15}$ In some patients the long-term administration of targeted therapy might affect immunity and predispose to life-threatening fungal infections. ${ }^{16}$ However, our patient was on imatinib therapy for one year only and developed these infections in blast crisis phase.

In a study of $100 \mathrm{CML}$ patients in chronic Phase the patients who received imatinib as first line therapy, with a median follow-up of 3.5 years, 17 infectious episodes were recorded in 16 patients (incidence 16\%). ${ }^{1}$ These infective episodes occurred at a median time of 13 weeks (range 9-26) from the onset of imatinib treatment. ${ }^{1}$ However, our patient presented after one year of imatinib therapy with Staphylococcus furunculosis and aspergillosis. Herpes zoster and pneumonia represented the two more frequently observed infections occurring in $7 \%$ and $4 \%$ of patients, respectively. ${ }^{1}$

To conclude, CML patients on Imatinib therapy are in a state of impaired immune response especially T-cell effector function. Although incidence of opportunistic infections in patients of CML on imatinib therapy are low, clinicians must be aware of atypical infections like aspergillosis that may occur in these patients. 


\section{Conflict of Interest: None}

\section{References}

1. Massimo Breccia, Corrado Girmenia, Roberto Latagliata et al. Low Incidence Rate of Opportunistic and Viral Infections During Imatinib Treatment in Chronic Myeloid Leukemia Patients in Early and Late Chronic Phase. Mediterr J Hematol Infect Dis 2011; 3(1): e2011021.

2. Cwynarski K, Laylor R, Macchiarulo E, Goldman J, Lombardi G, Melo JV, Dazzi F. Imatinib inhibits the activation and proliferation of normal T lymphocytes in vitro. Leukemia 2004; 18: 1332-1339.

3. Sinai $P$, Berg RE, Haynie JM, Egorin MJ, Ilaria RL, Jr, Forman J. Imatinib mesylate inhibits antigen-specific memory CD8 T cell responses in vivo. J Immunol 2007; 178: 2028-2037.

4. Chen $\mathrm{Cl}$, Maecker HT, Lee PP. Development and dynamics of robust T-cell responses to CML under imatinib treatment. Blood 2008; 111: 5342-5349.

5. Schlaberg R, Fisher JG, Michael J Flamm, Vundavalli V Murty, Govind Bhagat, Bachir Alobeid. Chronic myeloid leukemia and HIV-infection. Leuk Lymphoma 2008; 49(6): 1155-1160.

6. C Sillaber, Herrmann H, Bennett K, Rix U, Baumgartner $\mathrm{U}$, Böhm A et al. Immunosuppression and atypical infections in CML patients treated with dasatinib at 140 mg daily. Eur J Clin Invest 2009; 39(12): 1098-1109.

7. Yamaguchi J, Fujino T, Isa R, Nishiyama D, KuwaharaOta $S$, Kawaji $Y$ et al. Epstein-Barr virus-associated lymphoproliferative disease during imatinib mesylate treatment for chronic myeloid leukemia. Haematologica 2019; 104(8): e376-e379.

8. Mattiuzzi GN, Cortes JE, Talpaz M, Reuben J, Rios $M B$, Shan J et al. Development of Varicella-Zoster virus infection in patients with chronic myelogenous leukemia treated with imatinib mesylate. Clin Cancer Res 2003; 9: 976-980.

9. Miyazawa $Y$, Ishikawa $T$, Sugisaki $M$, Matsumoto $M$, Akashi M, Ishizaki T et al. Mediastinal abscess due to Aspergillus in a patient with atypical chronic myeloid leukemia, BCR-ABL1-negative. Rinsho Ketsueki 2020; 61(2): 128-130.

10. Akiyama $H$, Maruyama $T$, Uetake $T$, Kawaguchi $\mathrm{K}$, Sakamaki $\mathrm{H}$, Onozawa Y. Systemic infection due to atypical mycobacteria in patients with chronic myelogenous leukemia. Rev Infect Dis 1991; 13(5): 815-818.

11. Guarderas J, Karnad A, Alvarez S, BerkSL. Corynebacterium minutissimum bacteremia in a patient with chronic myeloid leukemia in blast crisis. Diagnostic Microbiology and Infectious Disease 1986: 327-330.

12. Pagano L, Caira M, Candoni A, Offidani M, Fianchi
F, Martino B et al. The Epidemiology Of Fungal Infections In Patients With Hematologic Malignancies: The SEIFEM-2004 Study. Haematologica 2006; 91: 10681075.

13. Nasir T, Lee C, Lawrence AS, Brown JS. Invasive aspergillosis complicating treatment with tyrosine kinase inhibitors. BMJ Case Rep 2019; 12(1): e226121. DOI: 10.1136/bcr-2018-22612

14. Deininger $M, O^{\prime} B$ rien SG, Guilhot F, Goldman JM, Hochhaus A, Hughes TP et al. International randomized study of interferon vs STI571(IRIS) 8-year follow-up: sustained survival and low risk for progression or events in patients with newly diagnosed chronic myeloid leukemia in chronic phase (CML-CP) treated with imatinib. Blood 2009; 114: 1126.

15. de Lavallade H, Apperley JF, Khorashad JS, Milojkovic $D$, Reid AG, Bua $M$ et al. Imatinib for newly diagnosed patients with chronic myeloid leukemia: incidence of sustained responses in an intention-to-treat analysis. $J$ Clin Oncol 2008; 26: 4806-4813.

16. Speletas M, Timoleon-Achilleas V, Klara F, Dimitrios Plastiras, Kyriaki Kokoviadou, Antonios Antoniadis, Ionnis Korantzis. Pneumonia caused by Candida krusei and Candida glabrata in a patient with chronic myeloid leukemia receiving imatinib mesylate treatment. Medical Mycology 2008; 46(3): 259-263. 